\title{
CAMPUR KODE DALAM PROSES BELAJAR MENGAJAR GURU BAHASA INDONESIA DAN SISWA KELAS XI ADMINISTRASI PERKANTORAN DI SMK NEGERI 1 SELUMA
}

\author{
Mahdijaya $^{1}$, Hasmi Suyuthi ${ }^{2}$, dan Melisa Oktarina ${ }^{3}$ \\ FKIP Universitas Muhammadiyah Bengkulu \\ mahdijaya354@gmail.com; hasmisuyuthi@umb.ac.id
}

\begin{abstract}
Abstrak
Permasalahan penelitian ini yaitu bagaimanakah bentuk dan faktor penyebab campur kode yang terjadi dalam proses belajar mengajar guru bahasa Indonesia dan siswa kelas XI Administrasi Perkantoran di SMK Negeri 1 Seluma? Tujuan penelitian ini adalah untuk mendeskripsikan bentuk campur kode dalam proses belajar mengajar guru bahasa Indonesia dan sisiwa kelas XI Administrasi Perkantoran di SMK Negeri 1 Seluma. Metode yang digunakan dalam penelitian ini adalah metode deskriptif. Data penelitian ini adalah ujaran-ujaran yang mengandung campur kode yang diucapkan oleh guru bahasa Indonesia dan siswa SMK Negeri 1 Seluma yang sedang melakukan kegiatan belajar mengajar di dalam ruang kelas XI Administrasi Perkantoran. Sumber data penelitian ini adalah guru bahasa Indonesia dan siswa SMK Negeri 1 Seluma yang sedang melakukan proses belajar mengajar di dalam ruangan kelas XI Administrasi Perkantoran. Teknik yang digunakan untuk mendapatkan data adalah teknik rekam dan teknik catat. Teknik analisis data adalah 1) pengumpulan data campur kode, 2) pengidentifikasian data campur kode,3) pengkategorian data campur kode, dan 4) penarikan kesimpulan. Berdasarkan hasil penelitian dapat disimpulkan bahwa bentuk campur kode yang terjadi dalam komunikasi guru bahasa Indonesia dan siswa kelas XI Administrasi Perkantoran di SMK Negeri 1 Seluma berupa kata dan frase yang berasal dari unsur bahasa Serawai dan bahasa Inggris. Faktor penyebab terjadinya campur kode dalam komunikasi guru bahasa Indonesia dan siswa kelas XI Administrasi Perkantoran di SMK Negeri 1 Seluma sebagai berikut: 1) keinginan penutur untuk menunjukkan keakraban dengan lawan bicara, 2) perubahantopik pembicaraan, 3) keinginan penutur menunjukkan identitas dirinya yang lebih memahami persoalan tertentu, dan4) faktor ketidaksengajaan penutur karena kebiasaan menggunakan bahasa tersebut dalam percakapan sehari-hari.
\end{abstract}

Kata Kunci: Campur Kode, Proses Belajar, Guru dan Siswa

\begin{abstract}
The problem of this research is how is the form and factors that cause code mixing that occurs in the teaching and learning process of Indonesian language teachers and students of Class XI Office Administration in SMK Negeri 1 Seluma? The purpose of this study was to describe the mixed forms of code in the teaching and learning process of Indonesian language teachers and class XI students in Office Administration at SMK Negeri 1 Seluma. The method used in this research is descriptive method. The data of this study are utterances that contain mixed codes spoken by Indonesian language teachers and students of SMK Negeri 1 Seluma who are conducting teaching and learning activities in class XI Office Administration. The data sources of this study were Indonesian language teachers and Seluma State Vocational School students who were conducting teaching and learning in class XI Office Administration. The technique used to get the data is the recording technique and the note taking technique. Data analysis techniques are 1) code-mixed data collection, 2) identification of code-mixed data, 3) categorization of code-mixed data, and 4) drawing conclusions. Based on the results of the study it can be concluded that the form of code mixing that occurs in the communication of Indonesian language teachers and students of Class XI Office Administration at SMK Negeri 1 Seluma in the form of words and phrases derived from elements of the Serawai language and English. The factors causing the occurrence of code mixing in the communication of Indonesian language teachers and students of class XI Office Administration at SMK Negeri 1 Seluma are as follows: 1) the desire of the speaker to show intimacy with the speaker, 2) the change in conversation, 3) the desire of the speaker shows his identity to better understand certain problems, and 4) the accidental factor of the speaker because of the habit of using the language in daily conversation.
\end{abstract}

Keywords: Mix Code, Learning Process, Teachers and Students

\section{PENDAHULUAN}

Bahasa merupakan alat komunikasi yang vital karena bahasa merupakan alat komunikasi

yang terpenting untuk berinteraksi. Bahasa memiliki fungsi untuk mengungkapkan atau 
menyampaikan informasi. Dengan adanya bahasa manusia dapat mengutarakan perasaan dan pikiran kepada orang lain.

Bahasa adalah milik manusia. Bahasa adalah salah satu ciri pembeda utama kita umat manusia dengan makhluk hidup lainnya di dunia ini. Dengan bahasa inilah manusia berinteraksi dan bekerja sama. Manusia tidak akan mampu bekerja sama tanpa menggunakan bahasa, bahasa itu digunakan untuk berbagi keperluan di berbagai lapangan hidup.

Bangsa Indonesia merupakan bangsa yang majemuk. Bangsa ini terdiri dari bermacam suku bangsa. Demikian pula setiap sukunya memiliki bahasa daerah sendiri. Adanya mobilitas antarmasyarakat menyebabkan terjadinya pencampuran bahasa yang akibatnya kontak dari individu-individu yang berasal dari daerah berbeda. Komunikasi yang terjadi saling menyesuaikan satu sama lainnya. Dwibahasa atau penggunaan dua bahasa bukan hal yang sulit ditemukan dalam komunikasi.

Kachru (dalam Suwito, 2002:76) memerikan batasan campur kode sebagai pemakai dua bahasa atau lebih dengan saling memasukkan unsur-unsur bahasa yang satu ke dalam bahasa yang lain secara konsisten. Salah satu ciri utama terjadinya campur kode ialah apabila suatu tuturan baik klausa maupun frasa-frasanya masing-masing tidak lagi mendukung fungsi tersendiri.

Penggunaan kode dalam komunikasi berarti memasukkan istilah-istilah lain dari bahasa yang dipergunakan. Penggunaan kode melalui proses campur kode dapat memberikan dampak positif terhadap kelangsungan komunikasi. Dengan penggunaan campur kode maka diharapkan komunikasi antara dua pihak atau lebih dapat berjalan efektif. Di samping itu, penggunaan campur kode dapat pula membuat pembicaraan lebih menarik.

Penggunaan dua bahasa ini sering kali ditemui dalam kehidupan sehari-hari. Demikian halnya dalam dunia pendidikan. Bahasa Indonesia dipergunakan sebagai bahasa pengantar dalam komunikasi di lingkungan sekolah dalam proses belajar mengajar. Seperti halnya di Provinsi Bengkulu yang dihuni oleh beragam masyarakat yang memiliki bahasa daerah asal masing-masing. Bahasa-bahasa daerah akrab didengar masyarakat Provinsi Bengkulu diantaranya bahasa Lembak, bahasa Rejang, bahasa Serawai, bahasa Mulak Bintuhan, bahasa Melayu Bengkulu, bahasa Pasema, bahasa Minang dan bahasa Jawa. Bahasa-bahasa daerah tersebut sering digunakan secara bergantian dengan bahasa Indonesia sebagai bahasa formal.

Banyaknya bahasa daerah ini tidak membatasi komunikasi antarmasyarakat. Terjadinya mobilisasi penduduk merupakan faktor penting terjadinya pencampuran bahasa untuk 
memperlancar proses komunikasi. Hal ini pula yang mendorong di antara masyarakat dapat menguasai lebih dari dua bahasa.

Di daerah Seluma, khususnya di SMK Negeri 1 Seluma, penggunaan bahasa daerah masih sering digunakan dalam proses belajarmengajar, masih seringkali guru menggunakan bahasa-bahasa daerah tertentu. Tujuannya untuk menerjemahkan materi pelajaran agar siswa dapat lebih mudah memahaminya.Penelitian campur kode ini dilakukan di SMK Negeri 1 kelas XI Administrasi Perkantoranyang terjadi pada saat pelajaran dimulai sampai proses belajarmengajar berakhir. Contoh kutipan campur kode yang terjadi di SMK Negeri 1 Seluma, pembicaraan seorang guru bahasa Indonesia dan seorang murid pada saat jam pelajaran bahasa Indonesia.

Guru (G) : Bayu, tolong ambilkan spidol bapak di kantor!

Siswa(S) : Yang warno hitam, Pak? (warna)

Guru $(\mathrm{G}): A u(\mathrm{Ya})$.

Pada percakapan di atas penutur siswa (S) melakukan campur kode dengan menyelipkan kata warno hitam (warna hitam) yang merupakan kata dalam bahasa Serawai ke dalam pembelajaran bahasa Indonesia. Campur kode dalam bentuk kata dilakukan guru (G)denganmengatakan kata au yang berarti $y a$.

Dalam realita yang dilihat bahwa di SMK Negeri 1 Seluma masih banyak komunikasi guru dan siswa yang menggunakan bahasa daerah. Oleh karena itu, peneliti akan melakukan penelitian tentang campur kodedenganjudul "Campur Kode dalam Proses Belajar Mengajar Guru Bahasa Indonesia dan Siswa Kelas XI Administrasi Perkantoran di SMK Negeri 1 Seluma”.

Berdasarkan latar belakang di atas rumusan masalah penelitian ini adalah (1) bagaimana bentuk campur kode yang terjadi dalam proses belajar mengajar guru bahasa Indonesia dan siswa kelas XI Administrasi Perkantoran di SMK Negeri 1 Selumadan (2) apa faktor penyebab terjadinya campur kode dalam proses belajar mengajar guru bahasa Indonesia dan siswa kelas XI Administrasi Perkantoran di SMK Negeri 1 Seluma.

\section{METODE PENELITIAN}

Metode yang digunakan dalam penelitian ini adalah metode deskriptif. Metode deskriptif adalah suatu metode dalam meneliti status sekelompok manusia, suatu objek, suatu set kondisi, suatu sistem pemikiran, ataupun suatu kelas peristiwa pada masa sekarang (Nazir, 2009:54). Metode deskriptif dalam penelitian ini digunakan untuk mendeskripsikan campur kode dalam komunikasi guru bahasa Indonesia dan siswa SMK Negeri 1 Seluma. 
Data penelitian ini adalah campur kode dalam ujaran-ujaran yang mengandung campur kode yang diucapkan oleh guru bahasa Indonesia dan siswa kelas XI Administrasi Perkantoran di SMK Negeri 1 Seluma yang sedang melakukan kegiatan belajar mengajar di dalam ruang kelas.

Sumber data penelitian ini adalah guru bahasa Indonesia dan siswa kelas XI Administrasi Perkantoran di SMK Negeri 1 Seluma yang sedang melakukan proses belajar mengajar di dalam ruangan kelas.

Instrumen utama penelitian ini adalah peneliti. Instrumen sebagai alat bantu dalam menggunakan metode pengumpulan data merupakan sarana yang dapat diwujudkan dalam benda, misalnya angket, perangkat tes, pedoman wawancara, pedoman observasi, skala dan sebagainya. Dalam penelitian ini peneliti menggunakan tabel sebagai instrumen pembantu.

Tabel 1

Percakapan Guru Bahasa Indonesia dan Siswa SMK Negeri 1 Seluma

\begin{tabular}{|c|c|c|}
\hline No & Konteks & Percakapan \\
\hline 1 & & \\
\hline 2 & & \\
\hline
\end{tabular}

Tabel 2

BentukCampur Kode dalam Ujaran Guru dan Siswa Kelas XI Administrasi PerkantoranSMK Negeri 1 Seluma

\begin{tabular}{|c|c|c|c|c|c|c|}
\hline \multirow{2}{*}{ No } & \multirow{3}{*}{ Percakapan } & \multicolumn{5}{|c|}{ Bentuk Campur Kode } \\
\cline { 3 - 7 } & & Kata & Frasa & $\begin{array}{c}\text { Kata } \\
\text { Ulang }\end{array}$ & Ungkapan & Penyisipan \\
\hline 1 & & & & & & \\
\hline 2 & & & & & & \\
\hline
\end{tabular}

Teknik yang digunakan untuk mendapatkan data adalah teknik rekam dan teknik catat.Teknik rekam dilakukan dengan menggunakantaperecorder. 
Suwito (2002:8) berpendapat bahwa campur kode berdasarkan unsur kebahasaan dapat dibedakan menjadi 5 macam, yaitu campur kode dalam bentuk (1) kata, (2) frasa, (3) kata ulang, (4) ungkapan, dan (5) penyisipan

Kata adalah satuan terkecil dari kalimat yang mengandung sebuah ide atau makna;(2) Frase adalah satuan bahasa yang terdiri dari dua kata atau lebih yang tidak melampaui batas fungsi unsur klausa;(3) Kata ulang misalnya sudah waktunya kita menghindari "backing-backingan”, dan "klikklikkan"; (4) Ungkapan atau idiom misalnya pada waktu ini hendaknya kita hindari cara bekerja “alon-alan asal kelakon"; (5) Penyisipan bentuk baster (gabungan pembentukan asli dengan asing), penyisapan unsur yang berbentuk baster artinya bentuk baster atau kata campuran menjadi serpihan bahasa yang dimasukinya. Di dalam penelitian ini ditemukan 2 jenis campur kode, yaitu:

\section{Penyisipan Campur Kode Bentuk Kata}

Kata merupakan satuan terkecil dari kalimat yang mengandung sebuah ide atau makna. Terjadi campur kode berbentuk kata dalam komunikasi guru bahasa Indonesia dan siswa SMK Negeri 1 Seluma berarti masuknya serpihan-serpihan kata-kata dari bahasa lain ke dalam bahasa yang dipakai. Kata tersebut digunakan sebagaimana memperlakukan kosa kata bahasa tersebut. Pemaparan bentuk campur kode dalam komunikasi guru dan siswa di ruang kelas XI Administrasi Perkantoran akan dirinci sebagai berikut:

Percakapan 1, komunikasi ini berlangsung dalam kelas pada saat guru memulaiproses balajar mengajar. Percakapan berlangsung antara guru dan seorang siswa.

G : Jadi PR nya sudah dibuat?

$S$ : Sudah

G : Sudah ya! Belum selesai, oh belum di tulis. Ngapo belum di tulis? Nomer 1 kalian paham ya, nomer 2 paham, jangan sampai salah. Nomer 1 tentang negoisasi, hukum bikan?

$\mathrm{S}$ : Ya pak negoisasi

Berdasarkan percakapan di atas maka ditemukan serpihan kata yang mencampur ke dalam kode bahasa yang digunakan. Bahasa yang digunakan dalam percakan tersebut adalah bahasa Indonesia. Oleh penutur G terjadi campur kode dengan menyelipkan kata ngapo. Kata ngapo yang berarti kenapa. Kata tersebut merupakan kata dalam bahasa serawai. Dengan demikian penutur G telah melakukan campur kode dengan penggunaan dua jenis bahasa yakni bahasa Indonesia dan bahasa Serawai.

Percakapan 2, campur kode berbentuk kata dalam komunikasi guru dan siswa juga terjadi pada saat siswa terlambat masuk ke kelas melibatkan seorang guru dan beberapa siswa.

G : Oke ya, jadi hari ini akan membahas masalah struktural dalam bahasa Indonesia ditinjau dari jenis-jenis paragraf ya. Jadi, hari ini kita akan belajar kebetulan 
dalam bahasa Indonesia di tinjau dari jenis-jenis paragraf. Itu baru sampai ya Yandi?

S : Di sinilah pak.

G : Kiroi terlambat. Ini kenapa terlambat bertiga ini! Kenapa terlambat? Tinggal di?

S1 : Tenangan pak.

S2 : Talang Rami.

G : Tenangan, Talang Rami! Oke, jauh ya. Silahkan duduk! Jangan lagi terlambat. Saya saja tinggal di Papua sudah sampai. Makanya bangun pagi-pagi, tugasnya dikerjakan di rumah, jangan di sekolah. Nanti saya remidialkan semua, nanti saya ganti gurunya! Saya ngajar di kelas yang lain saja nggak ngajar kalian.

S : Jangan pak!

G : Makanya ada PR kerjakan. Oke ya, jangan lagi datang terlambat. Budayakan jangan datang terlambat ya, jangan-jangan ini kebiasaan telat kemarin ya? Bangunnya jam 8 jam 9.

S : Nggak pak!

G : Budayakan disiplin. Oke ya, jadi hari ini kita akan melanjutkan materi dari tuturan bahasa Indonesia di tinjau dari jenis-jenis paragraf.

Berdasarkan percakapan di atas maka di temukan serpihan kata oke yang berasal dari bahasa Inggris yang berarti baiklah dan kata kiroi yang berasal dari bahasa Serawai yang berarti kira. Dengan demikian penutur $\mathrm{G}$ telah melakukan campur kode dengan penggunaan tiga jenis bahasa, yakni bahasa Indonesia, bahasa Inggris dan bahasa Serawai. Maka dapat diketahui bahwa penutur G melakukan campur kode akibat dari kebiasaan menggunakan bahasa tersebut ketika proses belajar mengajar.

Percakapan 3, peristiwa campur kode terjadi di ruang kelas pada saat guru menanyakan jenis-jenis paragraf kepada siswa. Percakapan dalam komunikasi ini melibatkan seorang guru dan siswa.

G : Pakai baju seragam, kalau nggak mau pakai baju seragam sekolah yang tidak pakai baju seragam. Di kebun saja pakai baju seragam. Iya, nggak mungkin bajunya ganti-ganti. Baju ke kebun ini, ke sawah ini. Sekolah punya aturan, budayakan disiplin. Disiplin berpakain. Ada berapa jenis paragraf? Siapa yang tahu, Riki! Berapa Ki? Masa nggak tahu ada berapa. Na ketahuan bukunya tidak dibuka dirumah. Jangan-jangan begitu sampai rumah, tiduak. Ada berapa! Bukunya sudah saya fotocopy, baca di rumah! Ada berapa? Tidak tahu, bukunya tadi malam nggak di buka ya, ada berapa jenis?

S : Ada lima!

Kata dalam bahasa daerah yang di temukan dalam percakapan di atas adalah kata tiduakyang berasal dari bahasa Serawai yang berarti tidur. Proses campur kode yang dilakukan oleh penutur $\mathrm{G}$ merupakan faktor kesengajaan penutur karena kebiasaan menggunakan bahasa tersebut dalam percakan sehari-hari.

Percakapan 4, campur kode berbentuk kata dalam komunikasi guru dan siswa juga terjadi pada saat penutur $\mathrm{G}$ bertanya kepada siswa. 
G : Tuturan itu apa? Sebelum kita belajar tentang ini, apa tuturan! Siapa yang tahu, siapa yang keruan tuturan itu apa. Ada penutur dan ada mitra tutur. Apa itu penutur? Pembicara! Kalau mitra tutur pendengar atau lawan bicara. Nafa, kalau tuturan apa? Kalimat itu apa? Apa itu tuturan, siapa yang tahu. Kalau kalian bertemu dengan orang berucap nggak?

S : Berucap!

Berdasarkan percakapan di atas, ditemukan serpihan kata yang mencampur ke dalam kode bahasa yang digunakan. Bahasa yang digunakan dalam percakapan tersebut adalah bahasa Indonesia. Oleh penutur $\mathrm{G}$ terjadi campur kode dengan menyelipkan katakeruan yang berarti tahu.

Percakapan 5, campur kode berbentuk kata dalam komunikasi guru dan siswa juga terjadi pada saat guru menjelaskan tentang paragraf deskriptif melibatkan seorang guru dan siswa.

G : Kata-kata, melalui kato ya. Ini spidol, bentuknya bagaiman?

$\mathrm{S}$ : Panjang.

G : Panjang. Panjangnya berapa, satu jengkal, sekilan. Kemudian ini tubuhnya ya, tubuhnya ini warna?

S : Putih!

Percakapan di atas terjadi serpihan kata campur kode seperti kato dan sekilan yang berasal dari bahasa Serawai yang berarti kata dan sejengkal, faktor penyebab campur kode di atas dikarenakan penutur $\mathrm{G}$ ingin suasana belajar lebih akrab dengan siswa.

Percakapan 6, peristiwa campur kode juga terjadi di ruang kelas pada saat guru bahasa Indonesia menjelaskan materi yang disampaikannya.

G : Na itu bisa jadi, bentuknya bagaimana? Apakah bulat, apakah panjang, kalau roda belakangnya bulat roda bekangnya panjang, na itu menggambarkan objek. Kalau ukuran terserah apa panjangnya 3 meter. Kemudian kalau rasanya kita tidak bisa merasakan, paling merasakan ketika naik motor, oh enak naik motor ini, ketika bertemu dengan jalan buruk nggak terasa ya, itu rasa. Rasa itu tidak hanya pakai lidah, tapi pakai hati, paham nggak! Kemudian warna, motornya saya itu berwarna pink, motor saya warnanya orange, itu bagian warna. Sifatnya bagaimana? Tanya sendiri, motor sifat kamu bagaimana ya. Paham ya! Ini untuk deskripsi. Kalau bertemu ini bisa dikoran, oh ini jenis paragraf apa ya, bisa nggak membedakannya. Dia biasanya sifatnya menggambarkan objek secara jelas, secara rinci, misalnya anda praktik, kamu bertemu dengan orang-orang. Kamu magang dimana? Di PT.Pupuk Sriwijaya misalnya, kemudian luas gedungnya 3 meter x 40 meter, kemudian di sana jumlah karyawannya 2000 karyawan, kemudian bosnya bernama Pak Amir. Pak Amir itu sifatnya seperti ini seperti ini. $\mathrm{Na}$ itu namanya deskripsi. Oh, ternyata PT.Pupuk Sriwijaya itu karyawannya banyak, berapa? 2000, kemudian luas gedungnya 3 meter x 40 meter. Na itu namanya mendeskripsikan sebuah perusahaan. Paham?

S : Paham!

G : Kalau paham kita lanjut, kalau nggak paham tanyo! Silahkan tanyo kalau tidak paham. Paham nggak, paham ya! Mudah-mudahan paham. Maso sudah dijelaskan secara rinci dengan Pak Aceng, masih tidak jelas. Ini disoal-soal untuk ujian nasional, khususnya kelas 3, paling banyak tentang paragraf deskripsi, menggambarkan objek. Sama seperti kalian, ketika mau beli tas pasti lihat modelnya, bentuknya, warnanya, kemudian eh kantongnya banyak ya ada tempat 
duit receh, ada tempat duit 10 ribu, gayanya saja Pak. Ketika kalian melihat katalog, kita lihat katalog sofiemartin, pasti ada bentuk tasnya bagaimana, kemudian ukurannya berapa, 10x20 cm, adakan deskripsi gambar. Paham ya, ada pertanyaan? Kalau disuruh membuat paham?

S : InsyaAllah paham Pak.

Kata-kata bahasa daerah dan bahasa asing yang ditemukan dalam percakapan di atas adalah tanyo, maso, duit. Kata tanyoberarti tanya, kata maso berarti masa, kata duit berarti uang. Kata-kata tersebut merupakan kata-kata dalam bahasa serawai. Dengan demikian penutur G telah melakukan campur kode dengan menggunakan dua jenis bahasa yakni bahasa Indonesia dan bahasa Serawai. Dari percakapan di atas maka dapat diketahui bahwa tujuan penutur $G$ mencampur kode dalam percakan ini adalah agar siswa mudah memahami apa yang disampaikan oleh penutur G.

Percakapan 7, peristwa campur kode terjadi di ruang kelas pada saat guru sedang menjelaskantentang paragraf eksposisikepada siswa.

G : Apa kerjaan Supartono? Menggantikan kepalanya? Apa kerjaannya, yang dikerjakan apa?

S : Mengaktifkan Pak.

G : Mengaktifkan, sama-sama belajar ya. Oke, kita lanjut yang kedua. Yang kedua ini eksposisi atau eksposisif. Apa itu eksposisi? Paragraf yang sifatnya, ketika kalian ingin membuat kue pasti ada sesuatu, ya ada tahap-tahap, apa itu kira-kira? Ketika kalian ingin membuat surat pasti ada tahap-tahap. Suratnya apa? Tentang apa, kemudian untuk siapa, diketik apa ditulis tangan, kertasnya kertas apa, pakai amplop atau tidak, capnya di mana, na itu namanya apa? Paragraf yang sifatnya?

S : Bertahap.

G : Bertahap, tetapi diapain?

$\mathrm{S}$ : Dijabarkan.

G : Kalian misalnya mau membuat kue, kuenya kue bolu brownies, pertama ambil apa? Bahan kan! Alatnya nanti, kalau bahannya nggak ada alatnya ada gimana mau masak kuenya, apa kira-kira, bahan. Bahannya apasaja, tepung terigu, tepung ini, tepung kanji, tepung itu misalnya, ini gula pasir, gula merah, gula apa. Itu ya, kemudian apalagi?

$S$ : Alat.

G : Air, masak kue kalau nggak pakai air gimana tu? Air kemudian alat-alatnya sudah ada, apa yang di masukkan? Pertama, tepung dulu, siram dengan air diaduk-aduk, siapkan tempatnya, dimasak, dimasukkan dalam loyang, hidupkan kompor. Jadi apa kira-kira? Terserah mau jadi apa, mau jadi cucur, mau jadi lumping, mau jadi apa terserah. Jadi, apa itu eksposisi? Sifatnya bertahap tetapi diuraikan. Paragraf yang sifatnya menguraikan secara rinci dan bertahap, ada tahap-tahapya. Ada langkah-langkahnya, jadi diuraikan. Ketika kita bangun tidur ngapain? Bangun tidur apa langsung makan, apakah langsung panaskan motor, apakah langsung pakai baju seragam sekolah, pergi nggak pakaimandi, nggak pakai makan, nggak pakai ngapa-ngapain. Itu artinya tidak beraturan, berarti tidak bertahap. Tapi, bangun tidur ngapain, cuci muka, sholat dulu kalau bangunnya subuh, kalau bangunnya jam 7, kebilo lagi sholat, sholat dhuha? Yang wajib bae tidak dilakukan mau sembahyang sunat, wajib dulu baru sunat. Tahu wajib?

S : Tahu.

G : Wajib itu apa? 
S : Kalau ditinggalkan berdosa, kalau dilaksanakan mendapat pahala.

Berdasarkan percakapan di atas, ditemukan beberapa serpihan kata yang mencampur ke dalam kode bahasa yang digunakan. Bahasa yang digunakan dalam percakapan tersebut adalah bahasa Indonesia. Oleh penutur G terjadi campur kode dengan menyelipkan kata-kata oke, kebilo, bae. Kata oke berasal dari bahasa Inggris yang berarti baiklah, sedangkan kata kebilodan bae merupakan bahasa Serawai yang berarti kapan dan saja. Dengan demikian penutur G telah melakukan campur kode dengan penggunaan dua jenis bahasa yakni bahasa Indonesia dan bahasa Serawai akibat dari kesengajaan penutur G supaya siswa lebih mudah untuk memahami apa yang disampaikan.

Percakapan 8, campur kode berbentuk kata dalam komunikasi guru dan siswa terjadi di dalam penyampaian materi pelajaran oleh seorang guru mata pelajaran bahasa Indonesia dan siswa.

G : Na itu tahu kan, kirain tidak tahu. Eksposisi, na ini bertahap, pertama ngapain, bangun tidur cuci muka ambil wudhu, sholat. Sudah itu ngapain, apakah bersih rumah, baru mandi, sarapan, kemudian motor dihidupkan, ambil tas, pergi. Eh lupa, uang sakunya mana, kalau belum dikasih uang saku mengut palak, dikasih 1000 merengut, 3000 senyum dikit, 5000 ketawa, ya itu kalian. Ya bertahap, diuraikan. Saya mau pergi ke sekolah, ini yang dilakukan. Itu namanya bertahap, diuraikan secara rinci. Masak kue tadi misalnya, masak kue itu bahannya ini di masukkan kemudian dimasak, bertahap ya, paham kan! Ketika kalian mau berangkat motornya diapain, motornya dikeluarkan, dipanaskan, digas baru berangkat, ya itu bertahap. Nggak mungkin motornya nggak digas, dan nggak dihidupkan, nggak bakal hidup. Ini eksposisi, uraian secara bertahap. Kalau di koran bisa membedakan? Ketika kalian sakit, minum obat, na di belakangnya kan ada struknya tu, pertama dikocok dulu biar rata, maksudnya itu kan zat-zatnya di bawah yang di atasnya encer, di aduk dulu. Buka tutupnya, ambil sendok, minum deh, semoga lekas sembuh ya! Itu artinya apa, bertahap. Nggak langsung ambil botolnya, langsung minum, 2 jam $p u d u$. satu botol sirup obat demam diminum sekaligus seperti minum teh gelas. Operdosis berlebihan, kalau vitamin nggak apa-apa, ini paramex 4 buah sekali teguk, mangko alasannya kenapa biar gacang badu, biar cepat sembuh. Eksposisi paham ya, uraian secara bertahap. Yang ketiga apa Yandi? Yang ketiga apa Ndi? Kenapa lesu?pikiran di sini apa di mana?

$\mathrm{S} \quad$ : Di Tais.

G : Ngapain di Tais? Reno nggak ada lagi pikirannya ke sini, pikirannya cari beras.

$\mathrm{S}$ : Cari duit.

G : Cari duit untuk lebaran ini, itu pikirannya sekarang! Kalian nggak mengutpalak itu kenapa? Kawan lagi ngerayau, sebenarnya dia itu lagi fase-fasenya ngerayau, fase cari beras, jangan-jangan masia ngeghua kini. Persuasi apa? Selingan maksud saya, jadi konsentrasi ke sini, nanti dulu mikir kawin-kawin siapa pun itu ya.

S : Ya Pak!

Kata-kata bahasa daerah yang ditemukan dalam percakapan di atas adalah merengut, pudu, duit, ngerayau, dangeghua. Kata merengut merupakan kata dalam bahasa Serawai yang artinya cemberut, kata puduberarti habis, kata duit berarti uang, kata ngerayau berarti jalan-jalan, kata ngeghua berarti mendengkur. Dengan demikian penutur $\mathrm{G}$ telah mencampurkan campur kode 
dengan menggunakan dua jenis bahasa yakni bahasa Indonesia dan bahasa daerah Serawai. Dari percakapan di atas maka dapat diketahui bahwa tujuan penutur G mencampur kode dalam percakapan ini adalah faktor dari kesengajan karena kebiasaan sehari-hari.

Percakapan 9, campur kode berbentuk kata dalam komunikasi guru dan siswa juga terjadi pada saat proses belajar mengajar di dalam ruang kelas melibatkan seorang guru dan siswa.

G : Agar kita disiplin. Marilah kita pakai helm agar apa?

$\mathrm{S} \quad$ : Tidak kena tilang.

G : Itu yang terakhir, kalau diseggol anjing anda yang jadi korban. Kalau kalian ditabrak fuso, palak kalian di bawah ban fuso.

Berdasarkan percakapan di atas, ditemukan serpihan kata yang mencampur ke dalam kode bahasa yang digunakan. Bahasa yang digunakan dalam percakapan tersebut adalah bahasa Indonesia. Oleh penutur $\mathrm{G}$ terjadi campur kode dengan menyelipkan kata palak yang berarti kepala.

Percakapan 10, campur kode berbentuk kata dalam komunikasi guru dan siswa juga terjadi di dalam ruang kelas melibatkan seorang guru dan seorang siswa.

G : Tidak! Kalian ini pintar, pintar ngicu, pintar berbohong. Mau bayar LKS, begapo? Padahal 15000. Persuasif berarti ajakan, marilah kita korupsi agar apa? Belanjo. Kalau argumen apa? Argumen, pendapat yang disertai alasan. Sebaiknya sekolah kita ini di pagar, agar kenapa? Agar para monyet-monyet tidak berkeliaran, agar para Boy nggak bisa keliling. Kan banyak Boy di sekolah kita ini, Boy di sekolah kita nggak lulus kemarin. Tahun ini 3 atau 2 orang yang nggak lulus, sedih ya. Harus sekolah lagi kalau mau lulus tahun depan. Pendapat disertai alasan, mengapa sekolah kita ini harus di pagar, alasannya kenapa? Agar para monyet tidak berkeliaran. Yang merasa monyet, kelas ini ada tidak?

S : Nggak ada. Nido Pak!

Kata-kata bahasa daerah yang ditemukan dalam percakapan di atas adalah begapo, belanjo, dan nido. Kata begapo berarti berapa, kata belanjo berarti belanja, dan kata nido berarti tidak. Dengan demikian penutur $G$ telah melakukan campur kode dengan penggunaan dua jenis bahasa yakni bahasa Indonesia dan bahasa Serawai. Kata nidoyang diucapkan oleh penutur S-1 yang berarti tidak sebagai akibat kesengajaan karena kebiasaan sehari-hari.

Percakapan 11, campur kode juga terdapat dipercakapan ini. Yang dilakukan seorang guru bahasa Indonesia dan siswa pada saat menjelaskan materi pelajaran.

G : Kalian ketika SD, jatuh cinta. Na diangkat menjadi suatu cerita. Kalau pergi ke pantai, di pantai bertemu kenalan, itu kalian angkat menjadi sebuah cerita, bisa cerita pendek, bisa menjadi sebuah novel, bisa menjadi sebuah roman, na itulah namanya narasi. Tadi pagi saya ribut kudai dengan mak, ngapo? Minta duit LKS, itu narasi. Pagi tadi saya nabrak anjing, anjingnya mondar mandir, akhirnya tetumbur. Kalian senang nonton film Boy kan? Tahu Pak Aceng tu ya, itu judulnya apa?

S : Anak jalanan. 
G : Na, saya tadi malam kan tidak suka dengan film itu. Jujur, satu film Si Boy saya nggak suka, yang kedua Uttaran. Kalau ANTV pacak Pak lengitka, Pak hilangkan kudai. Karno ngapo gara-gara itu Pak nido jadi nonton berita. Terus film itu. Ya kan?

S : Ya, Pak.

G : Kenapa? Karena ada sesuatu. Kok judulnya anak jalanan! Ada daya tariknya, kenapa nggak judulnya Boy! Tapi, film yang saya sukai tadi malam itu Centini judulnya, senang saya. Kalau Boy, dikit-dikit balap.

S1 : Belago.

G : Ya kan! Balap, udim tu jatuh cinta. Dulu, saya senang film di Indosiar itu yang dikit-dikit kejam-kejam, senang saya. Tapi, akhirnya bosan. Sudah tahu alur ceritanya. Itu narasi itu ya, ada cerita. Sama kalian misalnya masa kecil kalian berteman dengan siapa ya, narasi ini adalah cerita, kisah, pengalaman, itu narasi. Kalian bertemu dengan ular, apa yang kalian rasakan? Bisa takut, bisa geli-geli, bisa sedih, tergantung kalian. Eh, ada ular besar misalnya, ularnya lagi meram apa, apa yang kalian rasakan? Pergi ke tempat buaya, lihat buaya besar. Apa yang kalian rasakan? Takut kan! Pergi kita melihat burung-burung, bulunya bagus, warna orange, hijau, ada warna pink. Apa yang kalian rasakan? Indah sekali, ya itulah namanya narasi. Pengalaman kalian, kalian sampaikan. Bisa merupakan cerita pendek, bisa menjadi sebuah novel, bisa menjadi sebuah roman. Apa itu roman?

S : Romantis!

G : Romantis! Itulah kicikan. Romantis itulah, rasanya dunia milik kita berdua, yang lain numpang. Ibarat katak dalam tempurung. Itu kalau lagi jatuh cinta ya. Paham ya?

S : Paham.

Berdasarkan percakapan di atas maka ditemukan beberapa serpihan kata yang mencampur ke dalam kode bahasa yang digunakan. Bahasa yang digunakan dalam percakapan tersebut adalah bahasa Indonesia. Oleh penutur G terjadi campur kode dengan menyelipkan kata-kata kudai, ngapo, tetumbur, pacak, lengitka, dan kicikan.Kata kudai yang berarti dulu, kata ngapo berarti mengapa, kata tetumbur berarti tertabrak, kata pacakberarti bisa, kata lengitka berarti hilangkan, dan kata kicikanberarti katakan yang berasal dari bahasa Serawai,sedangkan kata belago yang diucapkan oleh penutur S-1 sebagai akibat kesengajaan karena kebiasaan sehari-hari.

Percakapan 12, campur kode berbentuk kata dalam komunikasi guru dan siswa juga terjadi di dalam ruangan kelas melibatkan guru dan siswa.

G : Kalau saya, cocoknya di kebiri saja. Hidupnya nggak ada gunanya. Nggak ada nafsu, na itu artinya kalau umurnya 14 ditambah 10 kan 24. Hanya 10 tahun di penjara, nggak juga cocok. Kalau hukum mati, cocok nggak? Nggak juga cocok, kalau mati, sudah. Ditembak sudahdead. Ini pada teks-teks kriminal. Persuasi banyak di sosial, eksposisi banyak di tips. Misalnya cara menanam bunga, cara membudayakan. Misalnya anggrek, cara merawat mobil, na ini tips. Kalau deskripsi ya menggambarkan. Paham ya!

S : Paham.

G : Ada pertanyaan? Ada pertanyaan tidak? Betanyolah kalau ada pertanyaan. Masih ada waktu setengah jam lagi, ada pertanyaan tidak? Tidak! Itu di halaman berapa? 
S : 145 Pak.

G : na ini kan ada di halaman 145. Narasi bisa peristiwa, bisa fiksi dan nonfiksi, ini dibaca-baca di rumah. Ini, sekali lagi saya sampaikan, bahwa di kelas 3, ini masih bertemu dan banyak sekali materi ini di soal ujian. Makanya materi ini jangan dihilangkan dan dilupakan.nanti sudah dipelajari ada materi ini lagi, sudah lupa. Di saat ujian juga lupa, diingatkan. Kalau deskripsi menggambarkan objek, kalau eksposisi uraian, persuasi ajakan, argumen pendapat, narasi ada peristiwa atau kisah cerita, hanya itu kuncinya. Jadi, ditanya jangan nanti hari ini dapat besok lupa lagi. Ditanya lupa lagi. Na sama kalian nonton anak jalanan, itu narasi. Cerita, bisa fiktif, bisa non fiktif, apa itu fiktif?

S : Nyata.

G : Kalau non fiktif?

$\mathrm{S} \quad$ : Tidak nyata.

G : Tidak nyata., menghayal, kalaian belum pernah pacaran menghayal pacaran, itu non fiktif. Paham ya! Bahwa pemikiran kalian itu orang pacaran pegangan tangan, jalan berdua, karena kalian belum mengalami. Padahal pacaran tidak seperti itu. Kalian menjaga, kalian menghargai, itu namanya pacaran. Tidak jalan berdua, pegangan tangan, minum teh botol, tidak seperti itu. Tapi, saling menghargai dan saling menjaga. Silahkan kalau ada pertanyaan, bisa membedakan kelima jenis paragraf, jadi ada berapa jenis paragraf?

$\mathrm{S} \quad$ : Lima.

G : Diingat ya, nanti kelas 3 kalau bertemu dengan saya, ditanya paragraf bisa menjawab, saya nggak tahu di mana disuruh saya siap.

S : Pak saja Pak.

G : Sama saja ya.

S : Beda Pak.

G : Cuma beda saya lelaki dan dia perempuan. Alhamdulillah bahasa Indonesia yang saya ajar itu nilai tertinggi nomor 1 apa nomor 2 sekabupaten untuk bahasa Indonesia. Makanya belajar, nilainya 92. Bahasa Indonesia tertinggi di kabupaten, suatu kebanggaan.

S : Berkualitas Pak.

G : Bukannya berkualitas, sama-sama mau belajar. Ada PR kerjakan, nggak tahu bertanya. Ada pertanyaan tidak? Bertanyalah kalau ada yang ingin ditanyakan. Tidak ada! Nanti PRnya dikumpul ya, ada yang tidak buat? Kata saya kemarin cari yang warna ya?

S : Nggak Pak, kalau ada.

G : Biar lebih menarik. Oke, ada PR ya untuk minggu depan. "nomer 1 tulislah teks deskripsi keindahan bendungan Seluma!"

$\mathrm{S} \quad$ : Nido indah, Pak.

G : "Nomor 2 tulislah teks narasi tentang masa kecilku!" ketika saya kecil, saya ngapain, saya di mana. Paham ya! Na itu tugas kalian di rumah, di kumpul minggu depan. Oh ya, untuk paragrafnya paling sedikit 3 paragraf. 1 paragraf minimal 8.

$\mathrm{S}: 8$ kata.

G : Kalimat. Tahu kata nggak? "Amir, pergi," kalimat "Amir pergi ke pasar membeli durian." Itu kalimat. Bisa membedakan? Paham ya! Oke, jadi PR nya di kumpulkan. Untuk hari ini kita cukupkan, InsyaAllah kita bertemu selasa depan, jadi di rumah tolong belajar. Belajarlah bagus-bagus. Terimakasih.

Kata-kata bahasa daerah yang ditemukan dalam percakapan di atas adalah dead, betanyolah, dan oke.Kata deaddan okeberasal dari bahasa Inggris yang berarti meninggal dan baiklah, dan kata 
betanyolah berarti bertanyalah yang berasal dari bahasa Serawai. Dengan demikian penutur G telah melakukan campur kode dengan penggunaan tiga jenis bahasa yakni bahasa Indonesia, bahasa Inggris dan bahasa Serawai. Kata nidoyang diucapkan oleh penutur S-1 yang berarti tidak sebagai akibat kesengajaan karena kebiasaan sehari-hari.

\section{Penyisipan Campur Kode Bentuk Frase}

Frase merupakan satuan bahasa yang terdiri dari dua kata atau lebih yang tidak melampaui batas fungsi unsur klausa. Artinya frase tidak merupakan gabungan kata-kata yang memiliki/mengandung fungsi predikat. Temuan dalam penelitian ini menyebutkan bahwa campur kode tidak hanya terjadi dalam tuturan kata, melainkan juga terjadi campur kode dalam bentuk frase. Dari data yang diperoleh ditemukan dalam bentuk frase sebagai berikut.

Percakapan 1, berupa pembicaraan antara seorang guru (G) dan siswa (S) pada saat melakukan proses belajar mengajar.

G : Bapak mau tanya, jenis-jenis paragraf ada berapa? Ada berapa, siapa yang tahu. Jadi jenis paragraf ada berapa Yeri ado begapo?

S : Permisi pak! (siswa yang baru selesai mengganti pakaiannya masuk)

Pada percakapan di atas penutur G melakukan campur kode dengan menyelipkan frase ado begapo (ada berapa) yang merupakan frase dalam bahasa Serawai, pada peristiwa percakapan tersebut, percakapan terjadi antara guru dan siswa. Namun, dalam peristiwa tersebut guru dan siswa menggunakan bahasa Indonesia, hal ini disebabkan mereka sedang melakukan proses belajar mengajar. Faktor penyebab terjadinya campur kode pada percakapan yang diucapkan oleh penutur $\mathrm{G}$ di atas karena kebiasaan menggunakan kata-kata tersebut dalam percakapan sehari-hari.

Percakapan 2, campur kode berbentuk frase dalam komunikasi guru dan siswa terjadi di dalam penyampaian materi pelajaran oleh seorang guru mata pelajaran bahasa Indonesia dan siswa.

G : Itu tahu kan, kira tidak tahu. Eksposisi, na ini bertahap, pertama ngapain, bangun tidur cuci muka ambil wudhu, sholat. Sudah itu ngapain, apakah bersih rumah, baru mandi, sarapan, kemudian motor dihidupkan, ambil tas, pergi. Eh lupa, uang sakunya mana, kalau belum dikasih uang saku mengut palak, dikasih 1000 merengut, 3000 senyum dikit, 5000 ketawa, ya itu kalian. Ya bertahap, diuraikan. Saya mau pergi ke sekolah, ini yang dilakukan. Itu namanya bertahap, diuraikan secara rinci. Masak kue tadi misalnya, masak kue itu bahannya ini di masukkan kemudian dimasak, bertahap ya, paham kan! Ketika kalian mau berangkat motornya diapain, motornya dikeluarkan, dipanaskan, digas baru berangkat, ya itu bertahap. Nggak mungkin motornya nggak digas, dan nggak dihidupkan, nggak bakal hidup. Ini eksposisi, uraian secara bertahap. Kalau di koran bisa membedakan? Ketika kalian sakit, minum obat, na di belakangnya kan ada struknya itu, pertama dikocok dulu biar rata, maksudnya itu kan zat-zatnya di bawah yang di atasnya encer, diaduk dulu. Buka tutupnya, ambil sendok, minum deh, semoga lekas sembuh ya! Itu artinya apa, bertahap. Nggak langsung ambil botolnya, langsung minum, 2 jam pudu. satu botol sirup obat demam diminum sekaligus seperti minum teh gelas. Operdosis berlebihan, 
kalau vitamin nggak apa-apa, ini paramex 4 buah sekali teguk, supaya alasannya kenapa biar gacang badu, biar cepat sembuh. Eksposisi paham ya, uraian secara bertahap. Yang ketiga apa Yandi? Yang ketiga apa, Ndi? Kenapa lesu?pikiran di sini apa di mana?

$\mathrm{S} \quad$ : Di Tais.

G : Ngapain di Tais? Reno nggak ada lagi pikirannya ke sini, pikirannya cari beras.

$\mathrm{S}$ : Cari duit.

G : Cari duit untuk lebaran ini, itu pikirannya sekarang! Kalian nggak mengut palakitu kenapa? Kawan lagi ngerayau, sebenarnya dia itu lagi fase-fasenya ngerayau, fase cari beras, jangan-jangan masia ngeghua kini. Persuasi apa? Selingan maksud saya, jadi konsentrasi ke sini, nanti dulu mikir kawin-kawin siapa pun itu ya.

S : Ya Pak!

Pada percakapan di atas penutur G melakukan campur kode dengan menyelipkan frase mengut palak'sakit kepala' dan frase macang badu"cepat sembuh' yang merupakan frase dalam bahasa Serawai, pada peristiwa percakapan tersebut, percakapan terjadi antara guru dan siswa. Namun, dalam peristiwa tersebut guru dan siswa menggunakan bahasa Indonesia hal ini disebabkan mereka sedang melakukan proses belajar mengajar. Faktor penyebab terjadinya campur kode pada percakapan yang diucapkan oleh penutur $\mathrm{G}$ di atas adalah agar siswa mudah memahami apayang disampaikan oleh penutur G.

Percakapan 3, berupa pembicaraan antara guru dan siswa pada saat guru menceritakan ketidak sukaannya terhadap film.

G : Na, saya tadi malam kan tidak suka dengan film itu. Jujur, satu film Si Boy saya nggak suka, yang kedua Uttaran. Kalau ANTV bisa Pak hilangkan, Pak hilangkankudai. Karno ngapo? Gara-gara itu Pak nido jadi nonton berita. Terus film itu. Ya kan?

S : Ya Pak.

G : Kenapa? Karena ada sesuatu. Kok judulnya anak jalanan! Ada daya tariknya, kenapa nggak judulnya Boy! Tapi, film yang saya sukai tadi malam itu Centini judulnya, senang saya. Kalau Boy, dikit-dikit balap.

Pada percakapan di atas penutur G melakukan campur kode dengan menyelipkan frase karno ngapo 'karena mengapa' dan 'tidak jadi' yang merupakan frase dalam bahasa Serawai, pada peristiwa percakapan tersebut, percakapan terjadi antara guru dan siswa. Ddalam peristiwa tersebut guru dan siswa menggunakan bahasa Indonesi,a hal ini disebabkan mereka sedang melakukan proses belajar mengajar. Faktor penyebab terjadinya campur kode pada percakapan yang diucapkan oleh penutur $\mathrm{G}$ di atas karena kebiasaan menggunakan kata-kata tersebut dalam percakapan seharihari.

\section{Faktor Penyebab Terjadinya Campur Kode}


Menurut Ohoiwutun (2002:71) terjadiya campur kode disebabkan beberapa faktor, seperti: a) keinginan penutur menunjukkan keakraban dengan lawan bicara; b) topik pembicaraan; c) keinginan penutur menunjukkan identitas dirinya yang lebih memahami persoalan tertentu; d) faktor ketidak sengajaan penutur karena kebiasaan menggunakan bahasa tersebut dalam percakan sehari-hari.

Berikut ini pemaparan faktor-faktor yang menjadi penyebab campur kode dalam proses belajar mengajar guru dan siswa kelas XI Administrasi Perkantoran di SMK Negeri 1 Seluma.

Percakapan 1, komunikasi ini berlangsung di ruang kelas pada saat guru memulai kegiatan proses balajar mengajar. Ditemukan campur kode oleh penutur $\mathrm{G}$ terjadi campur kode dengan menyelipkan kata ngapoyang berasal dari bahasa Serawai. Campur kode oleh penutur G disebabkan karena penutur $\mathrm{G}$ ingin menunjukkan keakrabannya kepada siswa.

Percakapan 2, campur kode berbentuk kata dalam komunikasi guru dan siswa juga terjadi pada saat siswa terlambat masuk ke kelas, ditemukan campur kode berupa kata oke dan kiroi yang disebabkan oleh kebiasaan penutur G menggunakan bahasa tersebut ketika proses belajar mengajar.

Percakapan 3, peristiwa campur kode terjadi di ruang kelas. Percakapan dalam komunikasi ini melibatkan guru dan siswa. di temukan dalam percakapan di atas adalah kata tiduakyang berasal dari bahasa Serawai yang berarti tidur. Proses campur kode yang dilakukan oleh penutur G merupakan faktor kesengajaan penutur karena kebiasaan menggunakan bahasa tersebut dalam percakan sehari-hari.

Percakapan 4, campur kode berbentuk kata dalam komunikasi guru dan siswa juga terjadi pada saat penutur $\mathrm{G}$ menjelaskan materi pelajaran kepada siswa. ditemukan serpihan yang menyelipkan kata keruan yang berarti tahu. Campur kode yang dilakukan oleh penutur G merupakan faktor kesengajaan penutur karena kebiasaan menggunakan bahasa tersebut dalam percakan sehari-hari.

Percakapan 5, campur kode berbentuk kata dalam komunikasi guru dan siswa juga terjadi pada saat proses belajar mengajar di dalam ruang kelas melibatkan seorang guru dan siswa, ditemukan campur kode berupa kata seperti kato dan sekilan faktor penyebab campur kode di atas dikarenakan penutur $\mathrm{G}$ ingin suasana belajar lebih akrab dengan siswa.

Percakapan 6, peristiwa campur kode juga terjadi di ruang kelas pada saat guru bahasa Indonesia menjelaskan materi yang disampaikannya. Ditemukan kata-kata bahasa daerah yang 
berupa kata tanyo, maso, dan duit. dapat diketahui bahwa tujuan penutur G mencampur kode dalam percakan ini adalah agar siswa mudah memahami apa yang disampaikan oleh penutur $\mathrm{G}$.

Percakapan 7, peristwa campur kode terjadi di ruang kelas pada saat guru sedang menjelaskan materi pelajaran. Ditemukan campur kode dengan menyelipkan kata-kata oke, kebilo, bae. Dengan demikian penutur $\mathrm{G}$ telah melakukan campur kode dengan penggunaan dua jenis bahasa yakni bahasa Indonesia dan bahasa Serawai akibat dari kesengajaan penutur G supaya siswa lebih mudah untuk memahami apa yang disampaikan.

Percakapan 8, campur kode berbentuk kata dalam komunikasi guru dan siswa terjadi di dalam penyampaian materi pelajaran oleh seorang guru mata pelajaran bahasa Indonesia dan siswa ini ditemukan bentuk campur kode berupa kata merengut, pudu, duit, ngeghua.Tujuan penutur G mencampur kode dalam percakapan ini adalah faktor dari kesengajan penutur karena kebiasaan menggunakan bahasa tersebut dalam percakapan sehari-hari.

Percakapan 9, campur kode berbentuk kata dalam komunikasi guru dan siswa juga terjadi pada saat proses belajar mengajar di dalam ruang kelas melibatkan seorang guru dan siswa, ditemukan serpihan kata palakyang mencampur ke dalam kode bahasa yang digunakan. Tujuan penutur $\mathrm{G}$ mencampur kode dalam percakapan ini adalah faktor dari keingian penutur untuk menunjukkan keakraban dengan lawan bicaranya.

Percakapan 10, campur kode berbentuk kata dalam komunikasi guru dan siswa juga terjadi di dalam ruangan kelas melibatkan seorang guru dan seorang siswa. Ditemukan serpihan katabegapo, belanjo, dan nido yang diselipkan oleh penutur $\mathrm{G}$ disebabkan oleh topik pembicaraan dalam percakapan tersebut, sedangkan kata nido oleh penutur S disebabkan faktor ketidaksengajaan penutur karena kebiasaan menggunakan bahasa tersebut dalam percakapan sehari-hari.

Percakapan 11, campur kode juga terdapat dipercakapan ini. Yang dilakukan seorang guru bahasa Indonesia dan siswa pada saat menjelaskan materi pelajaran. Oleh penutur G terjadi campur kode dengan menyelipkan kata-kata kudai, ngapo, tetumbur, pacak, lengitka, dan kicikan yang disebabkan oleh faktor keiginan penutur untuk menunjukkan keakraban dengan lawan bicaranya. Kata belagoyang diucapkan oleh penutur S-1 sebagai akibat dari keinginan penutur menunjukkan identitas dirinya yang memahami alur cerita film tersebut.

Percakapan 12, campur kode berbentuk kata dalam komunikasi guru dan siswa juga terjadi di dalam ruangan kelas melibatkan guru dan siswa. Serpihan kata campur kode yang ditemukan berupa katadead, betanyolah, dan okeyang diucapkan oleh penutur G yang diakibatkan dari faktor 
topik pembicaraan. Kata nidoyang diucapkan oleh penutur S-1 sebagai akibat ketidaksengajaan penutur karena kebiasaanmenggunakan bahasa tersebut dalam percakapan sehari-hari.

Percakapan 13, berupa pembicaraan antara guru $(\mathrm{G})$ dan siswa (S) pada saat melakukan proses belajar mengajar. penutur G melakukan campur kode dengan menyelipkan frase ado begapo, merupakan faktor kesengajaan penutur karena kebiasaan menggunakan bahasa tersebut dalam percakapan sehari-hari.

Percakapan 14, campur kode berbentuk frase dalam komunikasi guru dan siswa terjadi di dalam penyampaian materi pelajaran oleh guru dan siswa.Penutur G melakukan campur kode dengan menyelipkan frase mengut palak dan gacang badusebagai akibat ketidaksengajaan penutur karena kebiasaan menggunakan bahasa tersebut dalam percakapan sehari-hari.

\section{SIMPULAN}

Berdasarkan hasil penelitian dan pembahasan di atas, maka dapat diambil kesimpulan sebagai berikut.

1. Bentuk campur kode yang terjadi dalam proses belajar mengajar guru bahasa Indonesia dan siswa kelas XI Administrasi Perkantoran di SMK Negeri 1 Seluma berupa kata dan frase yang berasal dari unsur bahasa Serawai dan bahasa Inggris.

2. Faktor penyebab terjadinya campur kode dalam proses belajar mengajar guru bahasa Indonesia dan siswa kelas XI Administrasi Perkantoran di SMK Negeri 1 Seluma sebagai berikut.

a. keinginan penutur untuk menunjukkan keakraban dengan lawan bicara;

b. topik pembicaraan;

c. keinginan penutur menunjukkan identitas dirinya yang lebih memahami persoalan tertentu; dan

d. faktor ketidaksengajaan penutur karena kebiasaan menggunakan bahasa tersebut dalam percakapan sehari-hari.

\section{DAFTAR PUSTAKA}

Aslinda dan Leni Syafyahya. (2014). Pengantar Sosiolinguistik. Bandung : Refika Aditama.

Chaer, Abdul dan Leoni Agustina. (2010). Sosiolinguistik: Perkenalan Awal. Jakarta : Rineka Cipta. 
Ibrahim, Abd. Syukran. (2002). Panduan Penelitian Etnografi Komunikasi. Surabaya : Usaha Nasional.

Moleong, Lexy J. (2004). Metodologi Penelitian Kualitatif. Bandung : Tarsito.

Nababan, P.J.W. (2000). Sosiolinguistik Suatu Pengantar. Jakarta : Gramedia.

Nazir, Moh. (2009). Metodologi Penelitian. Jakarta : Ghalia Indonesia.

Pateda, Mansyur. (2001). Sosiolinguistik. Bandung : Angkasa.

Rusyana, Yus. (2001). Bahasa dan Sastra dalam Gamitan Pendidikan. Bandung : diponegoro.

Sumarsono, dan Paina Partana. (2002). Sosiolinguistik. Yogyakarta : SABDA

Suwito. (2002). Sosiolinguistik Pengantar Awal. Solo : Hanary Offset.

Tarigan, Henry Guntur. (2004). Pengajaran Kedwibahasaan. Bandung : Angkasa. 